\title{
Experiência e conhecimento
}

\section{José Luís Brandāo da Luz}

A preocupação da filosofia, persistentemente retomada, em certificar o nosso conhecimento da realidade tem insistido no propósito de identificar o terreno em que ele se poderá constituir, de forma incorrigivel. $\mathrm{O}$ projecto tem enfrentado repetidos reveses que, no entanto, não têm sido suficientemente fortes para enfraquecer a determinação de descobrir o que confere autenticidade ao conhecimento humano. Pelo contrário, tem dado lugar a diversas tentativas, nem sempre coincidentes entre si, decididas a enfrentar por sua conta o desafio que se poderá enunciar pela seguinte pergunta: que densidade ontológica possui um discurso que traduz a apropriação que o homem faz daquilo a que se refere?

Historicamente, a questão manteve-se polarizada por duas soluções que oscilaram entre a evidência apodíctica dàs ideias, à maneira de Descartes e de Husserl, e a imediatez intuitiva da experiência, conforme a exigência de Locke, Hume e Berkeley, tendo também passado pelo compromisso kantiano, que situava no juizo a mediação entre a apreensão intuitiva e a compreensão conceptual. O neopositivismo, que teria representado a última tentativa decidida a abordar o problema, em termos definitivos, optou por eleger o campo da experiência sensível como patamar de ligação entre o pensamento e a realidade. Porém, como iremos procurar analisar, a forma como concebeu esta ligação, que parecia não oferecer sinais de contestação, tornou-se obscura, deixando escapar toda a esperança epistemológica que a experiência prometia oferecer.

1. O neopositivismo, tomando as ciências da natureza e as matemáticas por fio condutor da sua orientação epistemológica, conforme o caminho também seguido pela Crítica da razão pura, teve em vista perceber em que bases se poderia assegurar ao conhecimento da natureza uma clareza analítica que o resguardasse de compromissos com a linguagem natural e as construções metafóricas, dois focos de persistentes imprecisões e obscuridades. Pela análise lógica da linguagem seriam eliminadas todas as ambiguidades que distorcessem a significação autêntica do conhecimento científico e que alimentavam uma sabedoria de base impressionista, que o senso comum toma por inquestionável, ou um discurso paradoxal, que se inspirava na clarividência que uma intuição intelectual pudesse propiciar, mas que não ofereceria outra consistência senão a que resultasse da convicção que cada um lhe conceder.

As linhas programáticas da concepção neopositivista convergem no propósito de clarificação do discurso das ciências por meio da linguagem unificada da lógica. O Manifesto, que definia as linhas programáticas do grupo de Viena, elege como tarefa identificar os enunciados dotados de significação, pela redução dos conceitos que entram na sua formação aos correspondentes dados da experiência imediata, distinguindo-os assim dos que carecem deste fundamento. Tomam simultaneamente por princípios, quer a experiência, que consideram ser a única fonte que poderá fazer 
crescer o conteúdo do conhecimento ${ }^{1}$, quer o carácter analítico que este deverá revestir, na convicção de que «todo o pensamento, toda a inferência, não consiste em outra coisa senão numa transposição de enunciados para outros enunciados que não contêm nada que não estivesse já nos primeiros (transformação tautológica)»².

A forma como Wittgenstein concebeu a relação entre o mundo e o pensamento influenciou as posições dos membros do Círculo de Viena, que comentavam com particular entusiasmo o Tractatus logico-philosophicus, a primeira grande obra do filósofo austríaco. Na concepção do Tractatus, a nossa representação do mundo faz-se em termos não existenciais, mas na perspectiva da sua possibilidade. Doutro modo, estaríamos circunscritos aos contornos estáticos que delimitam as diferentes entidades do mundo físico. O pensamento contempla o domínio das possibilidades que constituem um espaço lógico, movendo-se portanto numa rede de relações, susceptível de informar discursivamente todas as projecções possíveis referentes ao mundo real. Todavia, apesar das projecções do pensamento terem o mundo como horizonte, elas não contemplam a sua existência, já que o mundo a que o pensamento se refere são apenas «factos» que pertencem exclusivamente a um espaço meramente lógico ${ }^{3}$. Desta forma, as representações ou imagens que constituem o pensamento e se comunicam pela linguagem, não se apresentam como uma reprodução da realidade percebida na experiểncia sensivel, mas constituem antes o seu modelo. São comparáveis à pintura das cenas da vida real representadas num quadro, ou à forma como a escrita hieroglífica evoca os factos a que se reporta, ou ainda ao modo como as estrias dum disco fonográfico ou as notas musicais duma partitura registam uma peça musical: todas elas se compreendem como a projecção duma realidade, que pode vir a ter ou não ter existência ${ }^{4}$.

Porque o pensamento pertence ao domínio da lógica e as coisas, ao domínio da existência, não está garantida a correspondência entre o pensamento e o mundo. A ligação entre estas duas esferas faz-se por meio duma representação ou imagem, que "é um modelo da realidade»", que só será verdadeiro se concordar com ela ${ }^{6}$, pois a proposição que o exprime refere a "projecção» da realidade, «mas não o que é projectado» ${ }^{7}$. E assim como uma melodia pode ser extraida duma partitura musical ou das estrias dum disco fonográfico, também a realidade do mundo pode ser conhecida pela sua representação proposicional, sem que tal implique a sua existência. A pauta musical é uma imagem da melodia, como «a proposição é uma imagem da realidade tal como nós pensamos $»^{8}$. Em si mesma, uma representação não é nem verdadeira nem falsa, senão quando a comparamos com a realidade, pelo que «o sentido da proposição é a sua concordância ou a sua não-concordância com as possibilidades da existência ou da não-existência de estados de coisas ${ }^{9}$. Compreende-se por isso que a representação duma proposição só possua realidade, isto é, só seja conhecida como verdadeira, quando puder exprimir algo de empírico que existe fora dela e de que possa ter experiência.

No entanto, esta experiência parece não mergulhar as suas raízes no ser, revelando ter dificuldade em romper as paredes que delimitam a sua imanência na consciência. Ela

1 Cf. H. Hahn, O. Neurath e R. Carnap, La conception scientifique du monde. Le Cercle de Vienne, em Antonia Soulez (org.), Manifeste du Cercle de Vienne et autres écrits, Paris, PUF, 1983, p. 127.

2 Ibidem, p. 117.

3 Cf. Ludwig Wittgenstein, Tratado lógico-filosófico, trad. e pref. por M. S. Lourenço, Lisboa, Fundação Calouste Gulbenkian, 1987, 1. 13.

Cf. ibidem, 4. 014-4. 016.

Ibidem, 2. 12.

Cf. ibidem, 2.21 e 2.222.

Ibidem, 3. 13.

Ibidem, 4. 01.

9 Ibidem, 4.2. 
traduz a forma como configuramos um objecto, limitando-nos ao que acontece, ou seja, aos «estados de coisas» ou aos «factos atómicos», que são apresentados como sendo as unidades básicas do real. Fica por restabelecer a analogia entre o pensamento e a realidade, ou seja, não percebemos como se assegura a autenticidade que as nossas representações aparentam ter. $\mathrm{O}$ mundo que a linguagem torna acessível constrói-se «com a ajuda de um andaime lógico $»^{10}$, pelo que permanece a questão de saber em que termos a linguagem nos comunica uma realidade ou está em conexão com o que exprime ${ }^{11}$.

2. A ideia de que a experiência sensível constituía a única base legítima do conhecimento científico serviu de denominador comum a todos os elementos do Círculo de Viena, mas foi também a porta de entrada das mais acesas controvérsias, que revelaram a falta de convergência no entendimento do seu significado. Carnap elegeu como principal preocupação a «reconstrução racional dos conceitos de todos os campos do conhecimento na base de conceitos que se referem aos dados imediatos», como declara no prefácio da segunda edição, de 1961, de A construção lógica do mundo. E logo de seguida esclarece o significado dessa construção racional, ligando-a à tarefa de lhes conferir uma maior clareza e exactidão, ou seja, de proceder à sua «explicação», conforme a expressão do prefácio da primeira edição da mesma obra. A linha de orientação assenta num procedimento reducionista de justificação dos conhecimentos numa base exclusivamente racional, em que contam, não «as acções dos cientistas, mas os seus

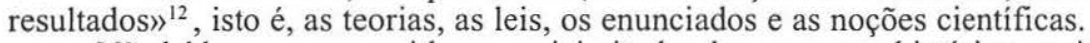

Não há lugar para considerar as vicissitudes dos percursos histórico, sociológico e psicológico que acompanham a investigação, mas apenas apreciar o carácter lógico da sua expressão linguística. O objectivo é, por um lado, estabelecer as regras de construção dos enunciados científicos, definindo como as proposições podem ser derivadas doutras e estas poderão, por sua vez, ser consideradas em função da natureza e da ordem das unidades elementares que as constituem, isto é, dos termos que formam o enunciado. Por outro lado, procura-se também empreender a determinação do seu significado pela experiência, na medida em que cada proposição, ao remeter para outras que explicam a sua construção, aparece como elemento duma cadeia que se prolonga até encontrar repouso nos elementos básicos que constituem os alicerces do sistema. Daí a designação de empirismo lógico que também é atribuída a esta influente corrente do pensamento epistemológico, pois, para além de considerar os conhecimentos em função das relações lógicas que permitem ordenar a sua expressão linguística, considera-os ainda em relação aos objectos que eles designam, atendendo assim não somente ao domínio da sintaxe mas também aos aspectos semânticos, que dizem respeito ao seu respectivo significado.

Esta questão encontra-se estreitamente ligada à tarefa de estabelecer as condições que tornam possível o sentido do enunciado, isto é, o seu conteúdo. Trata-se de compreender como um termo designa um objecto singular, uma propriedade sua ou uma função física, como a temperatura, a pressão, a densidade, etc., o que, segundo a tese defendida em A construção lógica do mundo, é assegurado pela sua ligação à experiência. Este processo de redução, que se designa por verificação, não se compreende, no entanto, como uma acumulação de dados empíricos, que se traduziria, por exemplo, na recolha de sucessivas sensações do Sol para se poder saber o que ele é. Pelo contrário, a exigência tem em vista a correspondência do conteúdo do enunciado com um determinado grupo de situações empíricas que o verificam, como acontece, por exemplo, com o aquecimento que observamos num fio condutor ou a oscilação duma agulha magnética. Estes são exemplos de fenómenos que «verificam» a passagem duma

12 R. Carnap, «Logical foundations of the unity of science», em Oswald Hanfling (org.), Essential Readings in Logical Positivism, Oxford, Basil Blackwell, 1981, p. 112. 
corrente eléctrica e dizem em que condições os enunciados revestem significado, ou podem ser tomados como exprimindo um conhecimento verdadeiro.

No entanto, os elementos sensoriais que conferem realidade ao conhecimento sistemático do mundo só se constituem em conhecimento quando são integrados por uma estrutura operativa que os articula. Doutro modo, «não seria possível avançar nenhum progresso construtivo para além deles» $\rangle^{13} \mathrm{e}$ estaríamos limitados a um amontoado de informações sem conexão alguma. Desta forma, as bases físicas a que o conhecimento se refere, revestem uma configuração subjectiva, sendo apenas consideradas como experiências dum sujeito individual. Pelo que a experiência apresenta assim uma configuração psicológica que «não só reflecte a ordem lógica da construção dos objectos, mas também a sua ordem epistémica» ${ }^{14}$, situando-se no mesmo terreno da interioridade da consciência a ordem operativa da construção do objecto, ou a sua integração no sistema geral de relações, e os elementos empíricos que lhe conferem realidade.

O conhecimento científico constrói-se pela articulação de várias proposições observacionais, que são o fundamento firme de qualquer ciência, mas tornou-se dificil estabelecer um entendimento na certificação desse conhecimento, ou seja, reconhecer a instância em que se confere significação às proposições, a qual, segundo as exigências neopositivistas, deveria situar-se na observação empírica imediata. Schlick insistiu em identificar um ponto de contacto entre o conhecimento e a realidade, que tornaria observacionalmente válidas as proposições que dão expressão aos enunciados científicos. Defendeu assim uma versão estrita da teoria verificacionista da significação dos enunciados científicos, segundo a qual é o dado incorrigível da experiência imediata que os verifica. A tese do Tractatus da ligação dos enunciados científicos aos «factos» ${ }^{15}$ era interpretada por ele, e também por Carnap e outros membros do grupo, como um reforço da sua perspectiva fenomenista, que remetia o significado da linguagem para a existência dos dados imediatos da consciência, que eram a expressão da experiência sensível.

Esta exigência de reduzir os enunciados científicos aos dados dos sentidos constituía uma cedência inaceitável a um pressuposto metafísico, impossível de verificar, tendo Otto Neurath defendido, em termos radicais, a natureza linguística da ciência. Revelando melhor entendimento das posições de Wittgenstein, insistiu na impossibilidade de ultrapassar as fronteiras da linguagem para encontrar os dados da experiência sensorial desprovidos de toda a conceptualização que a razão impunha. Tomando a física como modelo das ciências, foi a análise lógica da linguagem dessa disciplina que permitiu, ao nível da estrutura sintáctica do discurso, estabelecer a linguagem unitária de todas as ciências. Desta forma, a significação dum enunciado deixou de depender da sua redução aos dados imediatos percebidos pelos sentidos, mas antes da sua coerência interna, ou seja, da sua concordância ou ausência de contradição com os outros enunciados do sistema de conhecimentos que viabiliza a sua integração. A base empírica ou extralinguística da ciência, ao mesmo tempo que é revestida duma configuração de natureza metafísica, fragiliza o propósito verificacionista do programa inicial do Círculo e abre caminho a uma visão mais insegura da capacidade da experiência para certificar o valor de verdade de qualquer proposição.

Neurath sempre recusou aceitar que uma classe de enunciados observacionais pudesse servir de base certa e incorrigível ao conhecimento científico. Todo ele, nas suas diferentes manifestações, está sujeito a correcções, uma vez que não assenta os alicerces em rocha firme. Pelo contrário, está sempre na iminência de ser corrigido e de sofrer transformações, sendo semelhante a um barco que é obrigado a reparar as avarias

13 Ibidem, p. 98.

14 Ibidem, p. 101.

is Cf. Ludwig Wittgenstein, Tratado lógico-filosófico, 3. 21 e 4. 014. 
enquanto navega no alto mar, sem poder ser varado num porto ${ }^{16}$. Não poderemos dispor dum conhecimento do mundo a partir de «elementos últimos», cuja evidência os tornaria irrecusáveis. Uma linguagem ideal, construída a partir de proposições protocolares que nos proporcionasse uma visão directa da experiência do mundo físico e psicológico, como Carnap veio a defender, na sua fase fisicalista ${ }^{17}$, não passa duma ficção metafísica sem qualquer fundamento. O conhecimento científico compreende-se nos limites da discursividade linguística, pelo que uma perspectiva que alimente a ideia de apresentar a realidade em si ou de dispor duma linguagem privilegiada que a possa exprimir de forma incontestável reflecte preocupações e assenta em pressupostos de ordem metafisica totalmente inatingíveis.

Na sequência deste debate, mas também sob a influência das concepções convencionalistas de Poincaré, Duhem e da crítica de Karl Pooper, Carnap tomou consciência da impossibilidade duma verificação completa dos enunciados científicos, nomeadamente das leis e das teorias, e substituiu esta exigência inicial pelo princípio mais flexível da confirmabilidade. Porque a verificação obrigaria a efectuar um número infinito de observações a que um enunciado se refere, ela torna-se inviável, sendo preferível falar duma gradual confirmação, à medida que o número de casos observados, que é sempre limitado, não puser a descoberto nenhuma contrariedade ${ }^{18}$. Carnap pretendeu salvar as bases empíricas do discurso científico e evitar o solipsismo que a linguagem protocolar implicava. Para isso afastou dos enunciados as referências ao «conteúdo da experiência» e considerou-os apenas na sua configuração formal, ou seja, tomou as proposições protocolares na medida em que elas se referiam, não às coisas mesmas, mas aos termos que lhes dão expressão ${ }^{19}$. Procurou desta forma manter a base empírica da ciência, embora recuando do nível sensorial da experiência da realidade para a sua expressão linguística, que passou a ser valorizada por si mesma, como referência última e incorrigível dos enunciados científicos. Mas esta cedência carnapiana, na linha do convencionalismo, contribuiu apenas para comprometer ainda mais o propósito neopositivista de fundar o conhecimento nos dados imediatos da experiência e, para além disto, não deu satisfação à crítica que Neurath dirigiu a uma linguagem científica fora do contexto histórico em que se deveria integrar a sua significação e à necessidade de atender à sua compatibilidade com as proposições que constituem o sistema ${ }^{20}$.

É ilusório pensar que as proposições protocolares possam fixar o conhecimento da realidade duma forma definitiva. Qualquer enunciado científico, seja ele elementar ou de maior complexidade, como as leis e as teorias, está permanentemente sujeito a sofrer várias interpretações, isto é, está aberto à transferência de novos sentidos ou conteúdos. $\mathrm{O}$ apelo aos elementos básicos 'ou às proposições protocolares, para garantir uma certificação idónea aos enunciados científicos, confrontou-se sempre com uma série de indecisões quanto ao estatuto desses elementos. Mas o seu entendimento, ao evoluir duma concepção que ligava os enunciados aos estados de consciência que traduzem, de forma imediata, a experiência ou os fenómenos que são os factos conhecidos, para aquela outra que, sob pressão do fisicalismo de Neurath, circunscrevia a ciência à sua expressão linguística, contribuiu para um afastamento crescente da experiência do processo de justificação da veracidade do conhecimento. Certamente que a adesão de

16 Cf. Otto Neurath, "Protocol sentences», em Oswald Hanfling (org.), Essential Readings in Logical Positivism, Oxford, Basil Blackwell, 1981, p. 162.

17 Rudolf Carnap, "Protocol statements and the formal mode of speech», em Oswald Hanfling (org.), Essential Readings in Logical Positivism, Oxford, Basil Blackwell, 1981, p. 152.

18 Idem, "Testability and meaning», em Herbert Feigl e May Brodbeck (orgs.), Readings in the Philosophy of Science, New York, Appleton-Century-Crofts, 1953, pp. 58-59.

19 Cf. Idem, "Protocol statements and the formal mode of speech», pp. 158-159.

20 Otto Neurath, art. cit., p. 164. 
Carnap à concepção fisicalista não pôs em questão a possibilidade dos enunciados protocolares continuarem sendo uma base irredutivel dum conhecimento verdadeiro, mas este tornou-se cada vez menos susceptível de ser definido em termos de adequação e cada vez mais equacionável em termos de integração coerente no quadro do sistema da ciência.

Esta linha de orientação reporta-se a Berkeley, que muitos autores, entre os quais se inclui Popper, reconhecem ter exercido importante influência na forma como os filósofos do Círculo de Viena aceitaram partir da percepção dos dados da experiência como a fonte única do conhecimento. Porque para Berkeley, as ideias não possuem um conteúdo universal, elas são equiparadas às sensações e «só podem existir num espírito que as perceba $»^{21}$. O conhecimento que tenho das coisas exteriores, um objecto, um som, um odor, etc., não é possível sem a existência dum espírito que as pensa, isto é, que as vê, ouve, cheira, etc., sendo totalmente ininteligivel concebê-las com «uma existência natural ou real, distinta da sua perceptibilidade pelo espírito» ${ }^{22}$. O seu esse é percipi, conforme a bem conhecida máxima do filósofo irlandês. Tal não significa que a realidade do mundo não exista em si, ou que estejamos privados das coisas da natureza, mas apenas que o que podemos conhecer delas se reduz ao que percebemos, sendo destituído de sentido falar de realidades para além do que percebemos e «os filósofos chamam matéria ou substância corpórea» ${ }^{23}$. O empirismo lógico e Berkeley partilham em comum o apelo ao dado imediato da experiência percebido como fonte de sentido de todo o conhecimento, embora a forma como o subordinam à consciência acabe por esvaziá-lo de toda a densidade que ele prometia transportar.

3. O esforço de depuração para assentar na observação empírica imediata o conhecimento verdadeiro do mundo deixou sem resposta a questão do significado ou da consistência ontológica do conteúdo das proposições observacionais, nomeadamente, a sua presumível correspondência com os objectos do mundo real. Continua o debate para apurar em que termos a experiência faz oscilar a confirmação dum enunciado ou, por outras palavras, que ressonância tem a experiência na sua significação. Como Quine reconheceu, Carnap «foi o primeiro empirista que, não satisfeito em afirmar a redutibilidade da ciência aos termos da experiência imediata, empreendeu passos importantes para efectuar a redução» ${ }^{24}$. No entanto, embora tivesse reorientado o programa inicial do reducionismo empirista de Locke e de Hume, fazendo deslocar o principal veículo da sua significação do termo para a proposição, seguindo a linha de Frege, permaneceu prisioneiro do «dogma do empirismo».

Quine censura o propósito de Carnap de pretender mostrar que a verdade de cada enunciado se encontra associada a um determinado conjunto de acontecimentos da experiência sensível, cujạ ocorrência reforça o seu valor de verdade, transformando-o num enunciado analítico. É neste ponto que Quine recupera a tese de Duhem, que se opunha à possibilidade das chamadas experiências cruciais de Bacon, defendendo que «o físico nunca pode submeter ao controle da experiência uma hipótese isolada, mas somente todo um conjunto de hipóteses» ${ }^{25}$. A verdade dum enunciado teórico, em fisica, nunca se decide com base numa experiência física isolada, pois cada hipótese está sempre enquadrada num conjunto teórico que constitui um complexo homogéneo de relações. Uma teoria científica não constitui uma entidade simples e isolada, ou um aglomerado de elementos independentes uns dos outros, mas forma uma rede de noções,

21 George Berkeley, Tratado dos princípios do conhecimento humano, trad. e pref. de Vieira de Almeida, Lisboa, Imprensa Nacional-Casa da Moeda, 2000, § 3, p. 48.

22 Ibidem, § 4, p. 48.

23 Ibidem, § 35 , p. 58 .

24 Willard van Orman Quine, "Two dogmas of empiricism», em From a Logical Point of View, 2. ${ }^{\mathrm{a}}$ ed., Cambridge, Mass., Harvard University Press, 1994, p. 39.

25 Pierre Duhem, La théorie physique, son object et sa structure, 2. a ed. rev. e aumentada, Paris, Librairie Philosophique J. Vrin, 1997, p. 284. 
termos e leis que se implicam mutuamente. Nesta sequência, Quine considera o propósito reducionista de Carnap inconclusivo e avança com a sua concepção holista de que «as nossas proposições sobre o mundo exterior deparam com o tribunal da experiência, não individualmente, mas somente como um colectivo ${ }^{26}$. Logo de seguida acrescenta que «é absurdo, e constitui a raiz de muitos absurdos, falar duma componente linguística e duma componente factual da verdade de qualquer proposição individual. Tomada colectivamente, a ciência possui uma dupla dependência da linguagem e da experiência; mas esta dualidade não pode ser seguida significativamente nos enunciados da ciência tomados um a um» $)^{27}$.

Mesmo tomando como elemento-base do conhecimento científico a proposição, em lugar do termo, a sua significação não deriva dum elemento empírico isolado, mas da totalidade da ciência. Qualquer conflito provocado pela experiência no interior dum sistema de conhecimentos dá origem a um processo de reajustamentos e à reavaliação em cadeia de alguns dos seus enunciados, pelo menos dos que formam uma rede de ligações logicamente articulada. Quine compara o conhecimento científico ao nosso sistema de crenças, em que ambos são constituídos por um campo de forças que tem confrontações com o mundo da experiência. Os conflitos que a experiência provoca na periferia do campo repercutem-se no seu interior, nomeadamente ao nível das próprias leis lógicas, que formam a plataforma central do campo. Daí resultam reajustamentos inevitáveis, não apenas nas imediações, mas também nas parcelas de retaguarda, mais afastadas da fronteira com a experiência. A neutralização dos conflitos, tanto pode levar à preservação dos enunciados que se situam na zona mais exterior do campo, considerando-os vítimas de ilusões sensoriais, como pode também passar pela sua revisão, de modo a poder integrar a anomalia perturbadora, o que denota como a experiência, não só pode ser pouco relevante para condicionar as alterações no campo das ciências, mas também a maleabilidade que se dispõe para alterar o significado dos enunciados. Qualquer enunciado do sistema da ciência poderá ser submetido a revisão para ultrapassar o conflito com a experiência, mesmo aqueles que pela sua natureza se encontram distanciados da zona periférica do campo, como os enunciados teóricos da física, da lógica ou da ontologia, onde dificilmente se poderia reconhecer vestígios de conteúdos empíricos. Por esta razão o autor conclui ser um erro admitir semelhante ligação, afirmando mesmo que «nenhuma experiência particular está ligada com algum enunciado particular situado no interior do campo, excepto indirectamente, ou seja, através de considerações de equilíbrio que envolvem o campo na sua totalidade ${ }^{28}$. Desta forma, a afinidade que certos enunciados aparentam com experiências particulares apenas se poderá compreender como o reflexo duma provável dependência e, quando muito, um indicativo para determinar a escolha dos enunciados a rever.

Mesmo com relação aos objectos físicos a que certos enunciados se referem, se bem que, do ponto de vista duma atitude natural, acreditemos na sua existência frente a nós, no entanto, do ponto de vista epistemológico, os objectos a que, por exemplo, a microfisica se refere, assim como os que as leis e hipóteses teóricas da física contemplam «não são senão entidades que nós postulamos» ${ }^{29}$, da mesma forma que as entidades abstractas das matemáticas, que «facilitam as nossas relações com as experiências sensíveis $»^{30}$. Todas elas não passam senão de concepções que nos foram transmitidas culturalmente e que tiram a sua credibilidade da eficácia com que são capazes de dominar 0 «fluxo da experiência»" ${ }^{31}$. A experiência acaba por facultar a percepção do grau de

26 Willard van Orman Quine, «Two dogmas of empiricism», p. 41.

27 Ibidem, p. 42.

28 Ibidem, p. 43.

29 Ibidem, p. 45.

30 Ibidem.

31 Ibidem, p. 44. 
sucesso ou de eficácia que os enunciados científicos alcançam na realidade, servindo para confirmar as previsões que as ciências enunciam, mas deixa de constituir um veículo transmissor de significações, que assegura ao pensamento um enraizamento no ser.

Já anteriormente, Popper havia destruído as pretensões neopositivistas de justificar os enunciados científicos na experiência imediata, não somente por responder a um desígnio naturalista, mas por enfermar do vício mortal da lógica indutiva, segundo o qual só temporariamente a experiência poderá suportar um enunciado, ou seja, enquanto não ocorrer uma situação contrária que o desautorize ${ }^{32}$. A crítica de Popper representou uma incomodativa desvalorização do papel da experiência para firmar a objectividade do conhecimento. Apesar de admitir que só por meio da percepção poderemos tomar conhecimento dos factos, nega que esta tomada de consciência possa justificar a sua verdade. Esta perspectiva responde a uma orientação psicologista que julga poder atribuir à filosofia do conhecimento a tarefa de depurar as bases em que assenta o nosso conhecimento, em lugar de responder à pergunta: «como podemos provar as proposições científicas pelas suas consequências dedutivas? ${ }^{33}$. Este é um problema de natureza meramente formal que procura atender às conexões lógicas entre as proposições.

A orientação de Popper no tratamento do problema encaminha-o na direcção do convencionalismo, defendendo que o valor de verdade dum enunciado teórico é uma questão de preferência, ou seja, não se estabelece por via da sua redução à experiência, mas pelo sucesso que o confronto com a experiência lhe assegura. A analogia com o veredicto que os jurados pronunciam em tribunal relativamente ao apuramento da situação de facto em julgamento permite mostrar o significado da verdadeira consistência dum enunciado. O reconhecimento pelo tribunal da ocorrência do facto não poderá servir para garantir que ele é verdadeiro, até porque ele poderia ter sido apurado por maioria simples da votação dos jurados, ou vir a ser mesmo objecto de impugnação ou revisão. Significa apenas que foi admitido como verdadeiro em função dos dados que produziram a prova e poderá, em consequência, ser apreciado pelo juiz, em função do quadro legal em vigor. O mesmo acontece com os juízos de experiência, a sua constatação não significa a afirmação da sua verdade. Todavia, se eles não tivessem sido apurados nunca poderiam ser considerados pelo sistema teórico que torna possível a sua interpretação $0^{34}$.

Estamos em crer que estas concepções, ao desvalorizarem a importância da psicologia para compreender a ligação entre o pensamento e o ser perderam de vista a capacidade que Aristóteles descobriu na razão humana de poder ser todas as coisas. Estando pouco disponível para receber as informações da experiência, a razão acaba por reduzir toda a informação empírica ao que o jogo de conexões ou de relações formais é capaz de justificar, tornando-se muito pouco permeável ao «sabor» das coisas que a experiência percebe.

32 Cf. Karl Popper, The Logic of Scientific Discovery, New York, Basic Books Inc., 1961, pp. 33-37.

3 Ibidem, p. 98.

34 Cf. ibidem, pp. 108-110. 